\title{
Environmental quality of a stream can be better predicted by phylogenetic than by taxonomic diversity
}

\author{
Paweł Koperski ${ }^{1, *}$ and Robert Meronka ${ }^{2}$ \\ ${ }^{1}$ Department of Hydrobiology, Faculty of Biology, Biological and Chemical Research Center, University of Warsaw, Zwirki i \\ Wigury101, 02-089 Warszawa, Poland \\ ${ }^{2}$ Department of Ecology, Faculty of Biology, Biological and Chemical Research Center, University of Warsaw, Zwirki i Wigury101, \\ 02-089 Warszawa, Poland
}

\begin{abstract}
Different indices of taxonomic diversity (TD) and phylogenetic diversity (PD) of the macrobenthos were compared to determine the efficient predictors of environmental quality (EQ) in different types of watercourses in Poland. Archived data of 864 samples of benthic invertebrates identified to the family level were analysed on the basis of linear and non-linear multiply regression. The strengths of the correlations between two measures of EQ:BMWPpl (British Monitoring Working Party score system, Polish modification) and MMI (Multimetric Macroinvertebrate Index) and the values of taxonomic richness and three well-known TD indices: Shannon, Margalef and J' Evenness were compared to those for values of three PD indices, based on taxonomic distinctness. Taxonomic richness and all PD indices correlated more strongly with both measures of EQ than all TD indices. Correlations with both types of diversity indices were visibly stronger for BMWPpl when compared with MMI. We suggest that analysed indices of PD, especially MDis (mean phylogenetic distance between families in a sample), are related with EQ strongly enough to be taken into account as potential metrics in selection procedures of biological assessment.
\end{abstract}

Keywords: phylogenetic diversity / taxonomic diversity / macrobenthos / environmental quality / stream

Résumé - La qualité environnementale d'un cours d'eau peut être mieux prédite par la diversité phylogénétique que par la diversité taxonomique. Différents indices de diversité taxonomique (TD) et phylogénétique (PD) du macrobenthos ont été comparés pour déterminer les prédicteurs efficaces de la qualité de l'environnement (QE) dans différents types de cours d'eau en Pologne. Les données archivées de 864 échantillons d'invertébrés benthiques identifiés au niveau de la famille ont été analysées sur la base d'une régression linéaire et non linéaire. Les niveaux des corrélations entre deux mesures de QE : BMWPpl (système de notation du British Monitoring Working Party, modification polonaise) et MMI (Indice Multimétric des Macroinvertébrés) et les valeurs de la richesse taxonomique et trois indices TD connus: Shannon, Margalef et J d'homogénéité ont été comparés à ceux des valeurs de trois indices de PD basés sur la distance taxonomique. La richesse taxonomique et tous les indices de PD sont corrélés plus fortement avec les deux mesures de QE que tous les indices TD. Les corrélations avec les deux types d'indices de diversité étaient visiblement plus fortes pour BMWPpl que pour MMI. Nous suggérons que les indices analysés de la diversité phylogénétique, en particulier les MDis (distance phylogénétique moyenne entre les familles dans un échantillon), sont liés à une QE suffisamment forte pour être pris en compte comme mesure potentielle dans les procédures de sélection de l'évaluation biologique.

Mots-clés : diversité phylogénétique / diversité taxonomique / macrobenthos / qualité environnementale / rivière

\section{Introduction}

The history of the use of diversity indices in freshwater monitoring is long and complex and involves numerous methods (Magurran, 2004), especially the diversity of benthic

\footnotetext{
${ }^{*}$ Corresponding author: p.t.koperski@uw.edu.pl
}

invertebrates have been expressed in biological assessment in different ways (Bailey et al., 2004). Different indices of diversity description allow us to compare aquatic communities of different regions and types of environments, across taxa and trophic levels. However, the multitude of indices proposed for purposes of biological assessment makes biological diversity difficult to quantify. 
Environmental quality (EQ) of aquatic ecosystems is an overarching term coined by the Water Framework Directive (Directive 2000/60/EC of the European Parliament and of the Council - 2000) and is defined as a quality of structure and functioning (Furse et al., 2006). Taxonomic richness and diversity of aquatic organisms are considered as being among the most important parameters characterizing structure and functioning of lotic environments and describing the ecological status of an ecosystem. Therefore, different indices of diversity are of fundamental importance for environmental monitoring and conservation, although there is no consensus about which indices are more appropriate and informative (Yoccoz et al., 2001). A simple method of their classification is the division into: (1) measurement of taxonomic richness, (2) taxonomic diversity (TD) indices and indices describing (3) functional and (4) phylogenetic diversity (PD).

The suitability of TD indices for the biological assessment of freshwater environments seems to be as common as limited (e.g. Lydy et al., 2000). Commonly, assessment of benthic invertebrate diversity contains mixed- level taxonomic identification (taxa richness), species richness of selected taxa with high indicative value and total family richness (FR). Identification to the family level, (e.g. BMWP - British Monitoring Working Party score system, Armitage et al., 1983; FBI - Family-level Biotic Index, Hilsenhoff, 1988) seems to be a common compromise between cost, time and labour efficiency and the efficiency of EQ classification (Heino and Soininen, 2007). The advantages and disadvantages of different identification levels in biological assessment based on benthic organisms are still intensively debated (e.g. Bertrand et al., 2006; Jones, 2008; Koperski, 2011).

The weakness of traditional measures of TD seems to be a treating species or other taxa as being equal (Schweiger et al., 2008) in spite of their various functional divergence and phylogenetic distance. On the other hand, the use of TD indices based on identification to a level higher than the species is prone to different errors (Koperski, 2010, 2011; Šiling and Urbanič, 2016). Two groups of methods have been developed to solve these problems: "functional diversity" based on the analysis of the biological traits of benthic animals (e.g. Usseglio-Polatera et al., 2000) and PD based on mutual phylogenetic relationships between species (Warwick and Clarke, 1995; Faith and Baker, 2006). This type of diversity has been regarded as important for conservation planning and practice (Faith and Baker, 2006; Faith, 2015) and can be estimated by different measures of the distance between species or other taxa: taxonomic distance or distinctness (Clarke and Warwick, 1999), elapsed time of taxa divergence and genetic distance (Faith et al., 2009). Measuring diversity in terms of accumulated evolutionary history provides certain additional value to theoretical and applied ecology (Schweiger et al., 2008). Faith and Baker (2006) and Winter et al. (2013) demonstrated the suitability of molecular-based phylogenetic studies using barcoding methods for conservation ecology. Biological assessment of freshwater environments based on phylogenetic data of certain smaller taxa seems to be potentially effective and reliable (e.g. Vamosi and Vamosi, 2007; Carew et al., 2011). Crozier et al. (2005) conclude that the general applicability of PD is limited by the small proportion of taxa that have been reliably placed in a phylogeny.
The main aim of this study was to determine which type of benthos diversity is better predictor of EQ in different types of the watercourses. We used the strength of the relationships between different diversity indices and two measures of EQ, expressed as linear and non- linear regression coefficients and different measures of regression models' fit accuracy to achieve this aim. We assumed that the strength of correlation and fit accuracy of regression models' measures are the most important, decisive criteria to assess value of an index as a predictor of EQ. We tried to compare well-known TD indices currently used as metrics in biological assessments of EQ with PD indices in terms of their explaining value being a measure of their potential suitability. We expected that the indices based on phylogenetic relationships within benthic assemblages would be better correlated with EQ than indices based on TD and taxonomic richness. In this case, PD indices could be considered as a better tool to discriminate sites classified to different ecological statuses.

\section{Methods}

\subsection{Datasets}

The analysis as based on data archived at the Polish Head Inspectorate of Environmental Protection (www.gios.gov.pl) and those available online at the websites of 17 Regional (Voivodship) Inspectorates of Environmental Protection (RIEP). The databases contain taxonomic structure of invertebrates sampled once at 750 streams and rivers across Poland between 2009 and 2011 and identified to the family level. All samples were collected at fixed sampling sites, processed in the laboratory and identified by RIEP staff, according to the established procedure (multihabitat method of macrobenthos sampling RIVECO, Bis and Mikulec, 2013) in accordance with the assumptions of AQEM and STAR projects (STAndardization of River classification - a European Commission Framework V project) (Furse et al., 2006; Hering et al., 2006) and the requirements of the Water Framework Directive (2000). The database also contains classifications of each sampling site into one of 26 abiotic types and into one of six biocoenotic types of watercourses based on the structure of benthic assemblages at reference sites (Bis and Mikulec, 2013). Each part of the watercourse (flowing water body) can be classified into one of five ecological classes based on the values of BMWPpl (British Monitoring Working Party score system, Polish modification) and MMI (Multimetric Macroinvertebrate Index) - two indices based on structure of macrobenthic animals. Despite the generally accepted methodology quantifying the ecological status of any environment into separate classes (Directive 2000/60/EC), the EQ should be considered as a parameter showing a continuous distribution. BMWPpl is the original version of the well-known index BMWP (Armitage et al., 1993) implemented to Polish conditions as the official method of biological assessment (Kownacki et al., 2004). Index MMI is a multimetric biotic index, developed in accordance with objectives of the project STAR (Furse et al., 2006; Hering et al., 2006) and is currently the official method of biological assessment of watercourses in Poland (e.g. Lewin et al., 2014). Data from sites of biocoenotic types I and II (Tatra Mountains streams and western mountain/highland streams, 
Table 1. Number of sites classified to four biocoenotic types of watercourses and to five ecological categories on the basis of MMI and BMWPpl indices. Total number of invertebrate families in each type was added.

\begin{tabular}{|c|c|c|c|c|c|c|c|}
\hline \multirow[t]{2}{*}{ Biocoenotic type } & \multirow{2}{*}{$\begin{array}{l}\text { Families } \\
\text { found }\end{array}$} & \multicolumn{6}{|c|}{ Environmental quality (BMWPpl/MMI) } \\
\hline & & $\begin{array}{l}\text { Very } \\
\text { good }\end{array}$ & Good & Moderate & Poor & $\mathrm{Bad}$ & Total \\
\hline III - Eastern calcareous and siliceous upland streams and rivers & 112 & $34 / 9$ & $54 / 47$ & $45 / 51$ & $15 / 28$ & $6 / 19$ & 154 \\
\hline IV - Lowland sandy streams & 109 & $23 / 7$ & $46 / 35$ & $99 / 81$ & $44 / 76$ & $10 / 23$ & 222 \\
\hline $\mathrm{V}$ - Lowland streams and rivers, other than IV and V, and estuarine rivers & 133 & $40 / 7$ & $145 / 39$ & $103 / 152$ & $64 / 102$ & $11 / 63$ & 363 \\
\hline VI - Lowland rivers with organic bottom and lowland rivers connecting lakes & 113 & $22 / 2$ & $43 / 27$ & $41 / 54$ & $13 / 34$ & $6 / 8$ & 125 \\
\hline Total & 170 & $119 / 25$ & $288 / 148$ & $288 / 338$ & $136 / 240$ & $33 / 113$ & 864 \\
\hline
\end{tabular}

respectively) were omitted because of the low number of sites classified to certain quality classes. Data on 864 sites of four biocoenotic types (III-VI) were finally selected for further analysis (Tab. 1) after omitting incompletely described sites. The values of MMI equalling 0 were exchanged into very low positive values $(0.01)$ to enable the use of mathematical calculation.

\subsection{Diversity measures}

Three commonly used indices of TD were calculated for each sample: Shannon diversity index $H^{\prime}$, Margalef index $d$ and Evenness $J^{\prime}$ index (Equitability, Pielou, 1975) - all of them were applied to the taxonomic data following identification to the family level. We also included FR for each sample in the analyses. Database used for analyses, however, does not include detailed, direct data on number of animals in each sample, before and after procedure of subsampling, being the output values to subsequent calculations - though our calculations based on relative data on abundance present in database.

We created data matrix containing data of 117 families each (including Oligochaeta, which was regarded as a family in accordance to the procedure) collected at 864 sites to analyse phylogenetic relationships between animals. It was based on numerical data on family abundance and transformed into binary data of presence/absence. It contained data on the number of fixed taxonomic levels (suborder, order, subclasses, classes, subphyla, phyla and subkingdoms - value 1 for two families of the same suborder, value 8 for two families of different subkingdoms) between each pair of families in the database, based on the same assumptions as described in Clarke and Warwick (1999). The matrix was based on data available online at websites of Tree of Life (1995-2005), Encyclopaedia of Life (2011), NCBI Taxonomy (2014), and Wikispecies (2014). Four indices explaining phylogenetic relationships between benthic invertebrates sampled and identified to the family level were calculated:

- NRI - Net Relatedness Index (Webb, 2000);

- TPD - Total phylogenetic diversity scaled in taxa number of taxonomic levels between all pairs of families in a sample;

- MPD - Mean phylogenetic diversity scaled in taxa number of taxonomic levels between pairs of families in a sample divided into a number of families. This index is closely related to taxonomic distinctness by Clarke and Warwick (1999);

- MDis - Mean phylogenetic distance scaled in taxa number of taxonomic levels in each link between pairs of families in a sample divided into a number of families.

To avoid confusion about terminology, it must be emphasized that the indices based on number of taxa as a metric of distance between families are not treated as a measure of TD (such as Shannon, Margalef and Pielou J'evenness indices), but as a measure of PD.

\subsection{Data analysis}

To calculate values of PD indices, two software procedures were created in Visual Basic and applied into the data base in the Excel 2013 software package, Microsoft Office. Values of TD and PD indices for macrobenthos collected at the sampling sites were compared as predictors of EQ assessed for the watercourses. EQ at each sampling site was expressed quantitatively by the values of two biotic indices officially applied for the purposes of biological monitoring in Polish watercourses - BMWPpl and MMI. The type of best fitted mathematical function for each relationship between diversity indices and EQ measures was established using the trend analysis option in Excel 2013 software, based on the least squares method. In cases of nonlinear type of the relationship, adequate non-linear estimation and linearization procedures were performed. Estimated models of regression, being a subject of linearization procedure, were analysed and then evaluation of their fit accuracy were made with using module Multiply Regression in Statistica 12 software by Statsoft. Four statistical measures were selected as indices of fit accuracy: standardized coefficient of determination $R^{2}$, values of statistic $F$ for fit accuracy test of a model (higher values of both determine higher fitness of the model), Mean Absolute Error (MAE) and Residual Coefficient of Variation of the observed variable (lower values of the last two indices determine higher fitness of the model).

It must be added that FR, mathematically transformed values of BMWPpl (as ASPT index) and values of Shannon index are included into equation to MMI calculation as metrics and values of Margalef index are used in determining the ecological status with the BMWPpl method as an additional parameter. 


\section{Results}

We found linear function as the best fitted type of relationships between EQ measured by BMWPpl and indices of taxonomic richness (Fig. 1) and diversity: Shannon (Fig. 2), Margalef (Fig. 3), Pielou J' Eveness (Fig. 4). Linear function was also found as the best fitted one for relations between MMI and richness (Fig. 1) as well as between MMI and Shannon index (Fig. 2), while the best fitted function estimating relationships between MMI and Margalef and Pielou indices was multiplicative $\left(y=a \times x^{b}\right)$ (Figs. 3 and 4). Indices of PD TPD i MPD are related with both

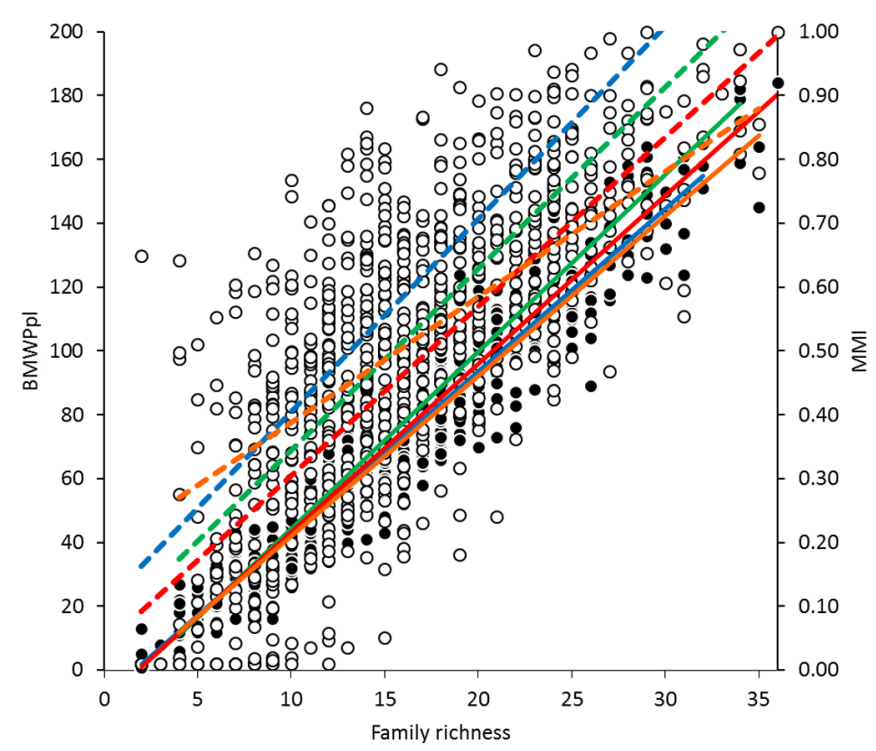

Fig. 1. The relationships between family richness of macrobenthos and values of environmental quality in four biocoenotic types of watercourses, expressed as the best fitted linear functions (green line - type III, blue line - type IV, red line - type V, orange line - type VI) and values of environmental quality measured by BMWPpl (black circles, solid lines) and MMI (white circles, dotted lines).

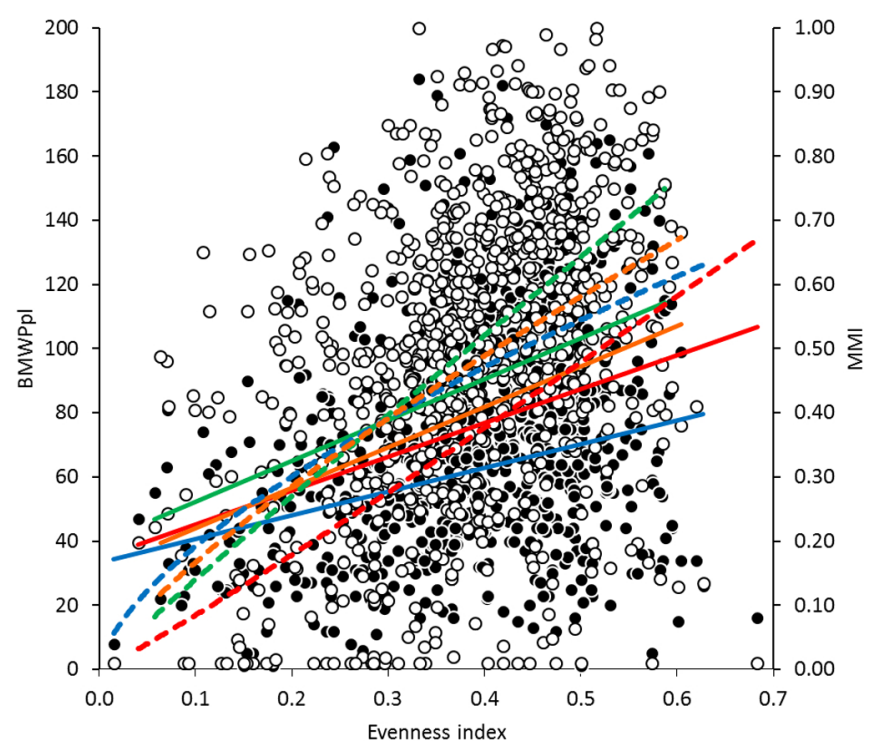

Fig. 2. The relationships between evenness index ( $J^{\prime}$ Pielou) in samples of macrobenthos from four biocoenotic types of watercourses (green line - type III, blue line - type IV, red line - type V, orange line - type VI) and values of environmental quality measured by BMWPpl (black circles, solid lines, best fitted linear functions) and MMI (white circles, dotted lines, best fitted multiplicative functions).

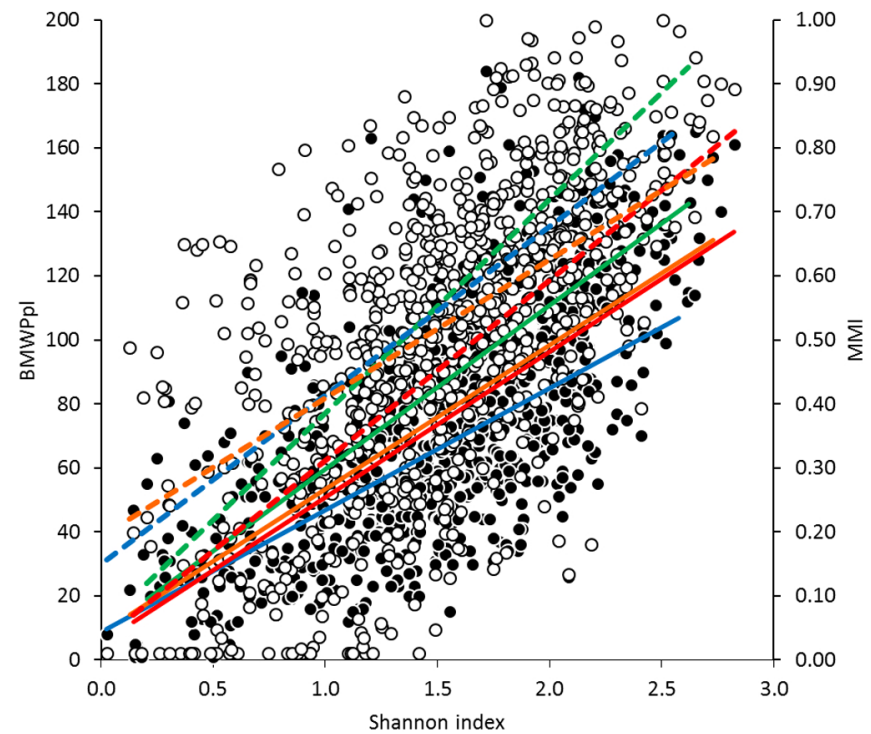

Fig. 3. The relationships between Shannon diversity index in samples of macrobenthos from four biocoenotic types of watercourses, expressed as the best fitted linear functions (green line - type III, blue line - type IV, red line - type V, orange line - type VI) and values of environmental quality measured by BMWPpl (black circles, solid lines) and MMI (white circles, dotted lines).

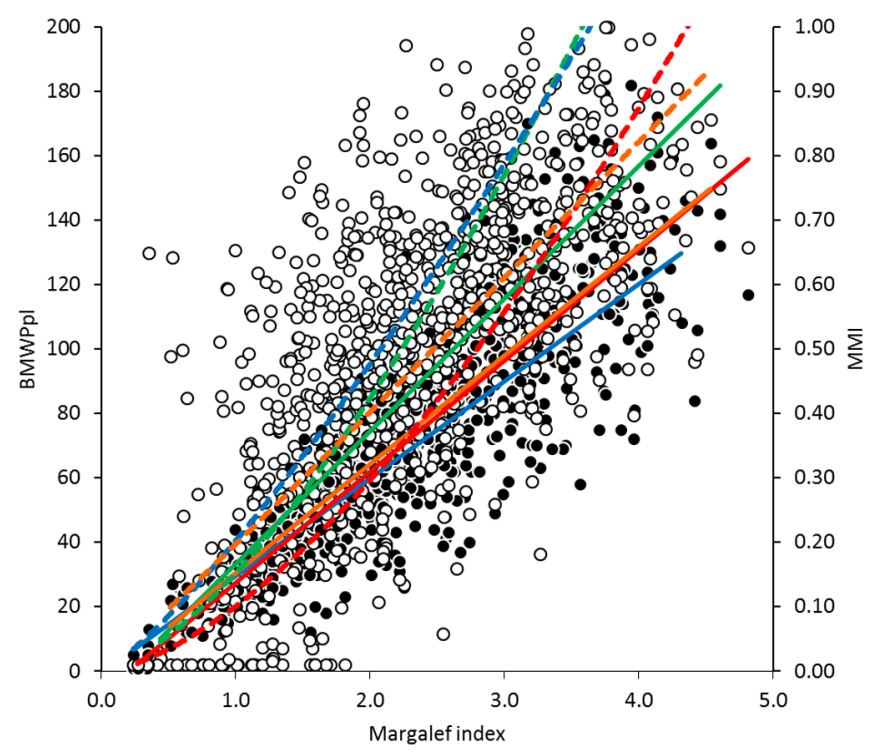

Fig. 4. The relationships between Margalef diversity index in samples of macrobenthos from four biocoenotic types of watercourses, expressed as the best fitted multiplicative functions (green line - type III, blue line - type IV, red line - type V, orange line - type VI) and values of environmental quality measured by BMWPpl (black circles, solid lines) and MMI (white circles, dotted lines). 


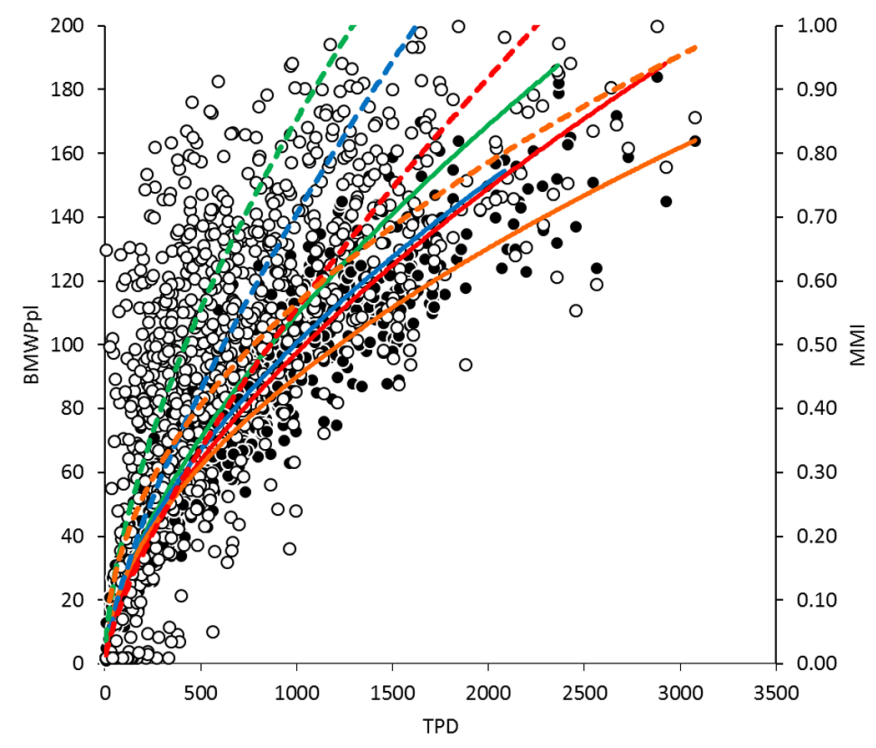

Fig. 5. The relationships between total phylogenetic diversity (TPD) in samples of macrobenthos from four biocoenotic types of watercourses (green line - type III, blue line - type IV, red line - type V, orange line - type VI) and values of environmental quality measured by BMWPpl (black circles, solid lines, best fitted linear functions) and MMI (white circles, dotted lines, best fitted multiplicative functions).

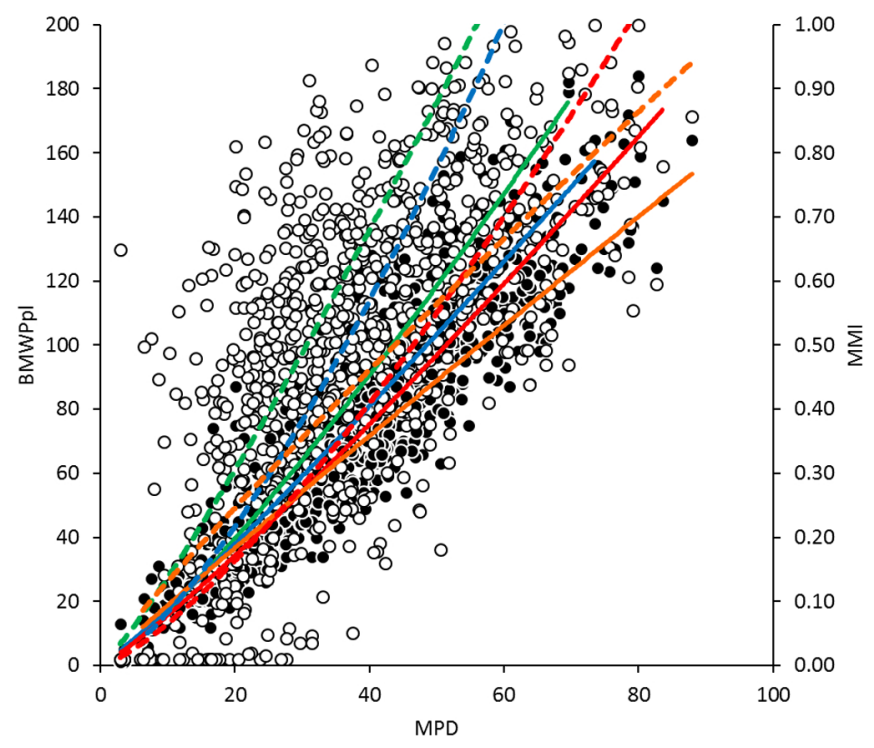

Fig. 6. The relationships between mean phylogenetic diversity (MPD) in samples of macrobenthos from four biocoenotic types of watercourses (green line - type III, blue line - type IV, red line type V, orange line - type VI) and values of environmental quality measured by BMWPpl (black circles, solid lines, best fitted linear functions) and MMI (white circles, dotted lines, best fitted multiplicative functions).

measures of EQ also along with multiplicative functions (Figs. 5 and 6), while relations between EQ and MDis index can be estimated by hyperbolic reciprocal function $(y=a+b / x)$ (Fig. 7).

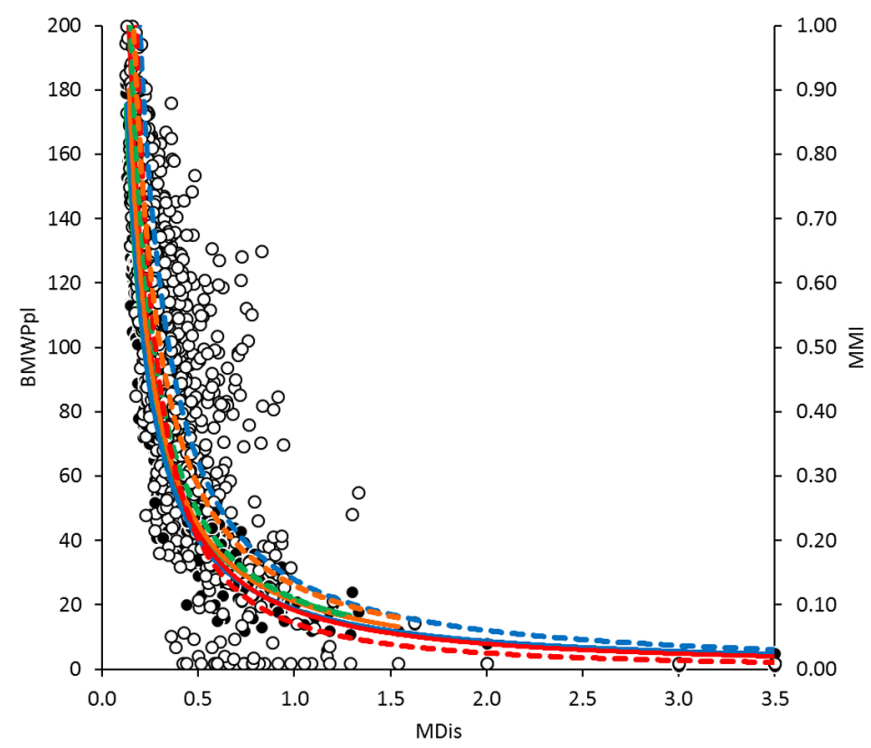

Fig. 7. The relationships between mean phylogenetic distance (MDis) in samples of macrobenthos from four biocoenotic types of watercourses (green line - type III, blue line - type IV, red line - type V, orange line - type VI) and values of environmental quality measured by BMWPpl (black circles, solid lines, best fitted reciprocal hyperbolic functions) and MMI (white circles, dotted lines, best fitted reciprocal hyperbolic functions).

All indices of PD, except NRI were strongly correlated with EQ measured by BMWPpl and their regression models after linearization procedure were well-fitted. Values of NRI were very weakly correlated with both measures of EQ ( $R^{2}$ ranged between 0.08 and 0.15 ). All three indices of TD in all types of watercourses had much lower values of $R^{2}$ and $F$ statistics and visibly higher measures of errors and residual variation (Tab. 2). Margalef index are a better predictor of BMWPpl than Shannon index in each case, while indices of regression fit accuracy for Evenness index were always very low. Indices of both PD and TD were more strongly related with EQ measured by BMWPpl than measured by MMI (Tab. 3). PD indices were also visibly better predictors of MMI than TD indices. Their values of $R^{2}, F$ and MAE show higher fit accuracy of regression models with exception of residual variation coefficient which varied between different types of watercourses (Tab. 3).

The highest fit accuracy and the highest predictive values were observed for FR and MDis index as predictors of EQ measured by BMWPpl. Their regression explained more than $90 \%$ of variation in EQ and values of errors are relatively very low. Those two indices were also the best predictors of EQ measured by MMI. The fit accuracy of regression models were generally the weakest in type III of the watercourses in case of BMWPpl, while those of VI type were the weakest in case of MMI.

\section{Discussion}

Our results clearly show that PD indices and taxonomic richness are much better predictors of EQ than TD indices. It seems consistent with suggestions of Gallardo et al. (2011) that 
P. Koperski and R. Meronka: Knowl. Manag. Aquat. Ecosyst. 2017, 418, 16

Table 2. Analysis of regression between environmental quality expressed by BMWPpl values and seven measures (indices) of macrobenthos diversity in four biocoenotic types of watercourses. Linearized regression functions and four measures of the fit accuracy are presented: mean absolute error (MAE), standardized $R^{2}$, values of statistic $F$ for regression model accuracy and residual coefficient of variation (RCV).

\begin{tabular}{|c|c|c|c|c|c|c|}
\hline Index & Type & Regression function & MAE & $R^{2}$ & $F$ value (df) & $\mathrm{RCV}$ \\
\hline \multirow[t]{4}{*}{ Shannon } & I & $y=51.19(4.45) x+8.57(7.27)$ & 88.29 & 0.467 & $132.5(1,151)$ & 35.31 \\
\hline & II & $y=38.03(2.82) x+8.71(4.15)$ & 59.47 & 0.452 & $180.8(1,221)$ & 35.85 \\
\hline & III & $y=45.58(2.44) x+4.97(4.07)^{\#}$ & 75.01 & 0.491 & $346.8(1,360)$ & 33.38 \\
\hline & IV & $y=44.89(4.34) x+8.51(7.39)^{\#}$ & 79.41 & 0.466 & $107.2(1,123)$ & 32.39 \\
\hline \multirow[t]{4}{*}{ Evenness } & I & $y=127.69(29.11) x+39.43(11.44)$ & 87.46 & 0.113 & $19.2(1,151)$ & 42.30 \\
\hline & II & $y=73.79(16.87) x+33.34(6.57)$ & 60.47 & 0.088 & $19.1(1,221)$ & 46.45 \\
\hline & III & $y=101.64(15.77) x+36.09(6.53)$ & 76.19 & 0.103 & $41.5(1,360)$ & 44.29 \\
\hline & IV & $y=126.09(28.05) x+31.42(11.43)$ & 80.63 & 0.141 & $20.2(1,123)$ & 41.06 \\
\hline \multirow[t]{4}{*}{ Margalef } & I & $y=41.21(1.67) x-7.99(4.13)$ & 89.51 & 0.802 & $610.6(1,151)$ & 24.45 \\
\hline & II & $y=30.17(1.30) x-0.55(2.85)^{\#}$ & 58.81 & 0.711 & $538.9(1,221)$ & 26.04 \\
\hline & III & $y=34.59(1.05) x-7.38(2.71)$ & 74.16 & 0.751 & $1088.5(1,360)$ & 23.32 \\
\hline & IV & $y=34.48(1.69) x-4.97(4.48)$ & 78.53 & 0.771 & $416.3(1,123)$ & 21.16 \\
\hline \multirow[t]{4}{*}{ Family richness } & I & $y=5.54(0.13) x-11.15(2.55)$ & 70.00 & 0.919 & $1731.0(1,151)$ & 12.72 \\
\hline & II & $y=5.09(0.10) x-8.31(1.49)$ & 47.29 & 0.920 & $2522.8(1,221)$ & 13.69 \\
\hline & III & $y=5.27(0.08) x-9.52(1.45)$ & 60.27 & 0.918 & $4067.2(1,360)$ & 2.44 \\
\hline & IV & $y=5.01(0.13) x-8.32(2.40)$ & 63.22 & 0.928 & $1588.4(1,123)$ & 2.25 \\
\hline \multirow[t]{4}{*}{$\mathrm{TPD}^{*}$} & I & $y=0.63(0.02) x+0.37(0.11)$ & 81.49 & 0.897 & $1313.5(1,151)$ & 5.16 \\
\hline & II & $y=0.59(0.01) x+0.56(0.08)$ & 55.04 & 0.895 & $1864.4(1,221)$ & 5.36 \\
\hline & III & $y=0.61(0.01) x+0.34(0.08)$ & 70.32 & 0.871 & $2422.7(1,360)$ & 5.36 \\
\hline & IV & $y=1.11(0.03) x+1.18(0.09)$ & 78.23 & 0.914 & $1315.0(1,123)$ & 3.56 \\
\hline \multirow[t]{4}{*}{ MPD* } & I & $y=1.19(0.04) x-0.09(0.16)^{\#}$ & 84.28 & 0.818 & $679.7(1,151)$ & 5.65 \\
\hline & II & $y=1.09(0.03) x-0.35(0.10)$ & 57.55 & 0.866 & $1419.7(1,221)$ & 5.82 \\
\hline & III & $y=1.13(0.03) x-0.14(0.10)^{\#}$ & 73.01 & 0.835 & $1817.9(1,360)$ & 6.06 \\
\hline & IV & $y=0.52(0.02) x-0.91(0.11)$ & 74.52 & 0.893 & $1027.5(1,123)$ & 3.98 \\
\hline \multirow[t]{4}{*}{ MDis* } & I & $y=20.29(0.55) x+6.33(2.42)$ & 83.82 & 0.901 & $1366.7(1,151)$ & 4.17 \\
\hline & II & $y=22.41(0.48) x-3.07(1.51)$ & 57.99 & 0.907 & $2144.1(1,221)$ & 4.75 \\
\hline & III & $y=25.50(0.48) x-4.39(1.63)$ & 73.41 & 0.889 & $2887.7(1,360)$ & 2.84 \\
\hline & IV & $y=23.99(0.69) x-0.23(2.51)$ & 77.64 & 0.909 & $1225.1(1,123)$ & 2.53 \\
\hline
\end{tabular}

* Denotes originally non-linear (intrinsically linear) relationship transformed into linear form (linearized).

${ }^{\#}$ Denotes non-significant constant.

certain measures of PD (distinctness) provide more valuable informations characterizing ecosystem quality, while Shannon diversity and taxonomic richness generate important informations on ecosystem conditions. PD indices, except NRI, seem to have a high potential value in biological assessment of freshwaters as they are more predictable and repeatable against BMWPpl than MMI. They seem to be strongly related to the type of watercourse when correlated with MMI - differences in determination coefficients between the biocoenotic types exceed 30\%. Strong and negative relations between MDis and BMWPpl in all types of watercourses make this index a suitable predictor of degradation.

Results of Carew et al. (2011) support the thesis about the existence of strong phylogenetic signals for degradation responses in macrobenthic animals. The explaining of biological causes and mechanisms of significant negative relationships between MDis values and EQ seems to be especially interesting and needs to be tested in further studies. It can be expected that increasing ecological stress (degradation) in a habitat results in the survival and occurrence of only a few or even single most resistant species of large taxonomic groups. This pattern can be extended from species to families containing, at degraded sites, only a single species. Finally, the phylogenetic distance between each pair of a few survivor families tends to increase at sites with low EQ, as opposed to decreasing values of total and MPD as well as TD and richness which is in line with findings of Warwick and Clarke (1995). Such reasoning supports the general idea that disturbance tends to affect riverine invertebrate richness negatively (see discussion in Lepori and Hjerdt, 2006). 
Table 3. Analysis of regression between environmental quality expressed by MMI values and seven measures (indices) of benthos diversity in four biocoenotic types of watercourses. Regression functions are presented and four measures of the fit accuracy: mean absolute error (MAE), standardized $R^{2}$, values of statistic $\mathrm{F}$ for regression model accuracy and residual coefficient of variation (RCV).

\begin{tabular}{|c|c|c|c|c|c|c|}
\hline Index & Type & Regression function & MAE & $R^{2}$ & $F$ value $(\mathrm{df})$ & $\mathrm{RCV}$ \\
\hline \multirow{4}{*}{ Shannon } & I & $y=0.33(0.03) x+0.05(0.04)^{\#}$ & 0.233 & 0.527 & $168.4(1,151)$ & 29.38 \\
\hline & II & $y=0.26(0.02) x+0.15(0.03)^{\#}$ & 0.394 & 0.394 & $142.5(1,221)$ & 33.28 \\
\hline & III & $y=0.28(0.02) x+0.31(0.03)^{\#}$ & 0.251 & 0.446 & $290.5(1,360)$ & 36.41 \\
\hline & IV & $y=0.21(0.03) x+0.19(0.05)$ & 0.393 & 0.281 & $48.04(1,123)$ & 58.11 \\
\hline \multirow{4}{*}{ Evenness* } & I & $y=1.09(0.17) x+0.16(0.07)$ & 0.370 & 0.218 & $42.0(1,151)$ & 37.80 \\
\hline & II & $y=0.62(0.12) x+0.28(0.05)$ & 0.452 & 0.102 & $24.9(1,221)$ & 40.51 \\
\hline & III & $y=0.81(0.09) x+0.15(0.04)$ & 0.287 & 0.159 & $68.3(1,360)$ & 44.88 \\
\hline & IV & $y=0.21(0.05) x+0.75(0.05)$ & 0.431 & 0.156 & $27.7(1,123)$ & 56.23 \\
\hline \multirow{4}{*}{ Margalef* } & I & $y=0.66(0.06) x-2.29(0.14)$ & 0.358 & 0.536 & $127.7(1,151)$ & 81.09 \\
\hline & II & $y=0.58(0.05) x-2.02(0.11)$ & 0.405 & 0.367 & $127.3(1,221)$ & 74.30 \\
\hline & III & $y=1.40(0.08) x-2.12(0.07)$ & 0.252 & 0.439 & $303.9(1,360)$ & 66.15 \\
\hline & IV & $y=0.48(0.03) x+0.31(0.03)$ & 0.398 & 0.289 & $50.2(1,123)$ & 58.19 \\
\hline \multirow{4}{*}{ Family richness } & I & $y=0.08(0.00) x+0.06(0.03)^{\#}$ & 0.120 & 0.639 & $266.9(1,151)$ & 25.68 \\
\hline & II & $y=0.03(0.00) x+0.10(0.03)$ & 0.113 & 0.586 & $310.3(1,221)$ & 27.50 \\
\hline & III & $y=0.03(0.00) x+0.04(0.02)^{\#}$ & 0.196 & 0.554 & $447.6(1,360)$ & 32.68 \\
\hline & IV & $y=0.02(0.00) x+0.19(0.04)$ & 0.119 & 0.452 & $101.4(1,123)$ & 45.36 \\
\hline \multirow{4}{*}{ TPD* } & I & $y=0.74(0.05) x-5.43(0.31)$ & 0.245 & 0.600 & $226.3(1,151)$ & 59.69 \\
\hline & II & $y=0.62(0.03) x-4.42(0.19)$ & 0.341 & 0.636 & $383.2(1,221)$ & 56.35 \\
\hline & III & $y=0.64(0.04) x-5.03(0.29)$ & 0.220 & 0.472 & $318.6(1,360)$ & 65.43 \\
\hline & IV & $y=1.03(0.12) x-3.66(0.35)$ & 0.122 & 0.405 & $90.9(1,123)$ & 45.14 \\
\hline \multirow{4}{*}{ MPD* } & I & $y=1.43(0.10) x-5.84(0.37)$ & 0.241 & 0.564 & $195.0(1,151)$ & 67.76 \\
\hline & II & $y=1.15(0.06) x-4.46(0.20)$ & 0.351 & 0.617 & $353.5(1,221)$ & 57.79 \\
\hline & III & $y=1.17(0.07) x-5.18(0.25)$ & 0.228 & 0.470 & $279.1(1,360)$ & 67.42 \\
\hline & IV & $y=0.48(0.06) x-3.91(0.39)$ & 0.126 & 0.392 & $79.3(1,123)$ & 49.55 \\
\hline \multirow{4}{*}{ MDis* } & I & $y=0.11(0.01) x+0.13(0.03)$ & 0.110 & 0.702 & $355.3(1,151)$ & 23.34 \\
\hline & II & $y=0.13(0.01) x+0.12(0.02)$ & 0.105 & 0.627 & $367.5(1,221)$ & 26.13 \\
\hline & III & $y=0.14(0.01) x+0.04(0.02)$ & 0.237 & 0.600 & $539.1(1,360)$ & 30.98 \\
\hline & IV & $y=0.09(0.01) x+0.21(0.03)$ & 0.117 & 0.490 & $118.2(1,123)$ & 41.42 \\
\hline
\end{tabular}

* Denotes originally non-linear (intrinsically linear) relationship transformed into linear form (linearized).

\# Denotes non-significant constant.

PD indices used in our study have clear limitations because their role has been restricted to analysis of an existing database. They are designed to process data from samples taken only once, differing in terms of abundance due to the use of subsamples and identified only to the family level. Despite such limitations, especially the use of a presence/absence data format, PD indices appear to be much better predictors of EQ than TD indices (Faith et al., 2009). A notable exception very weak response of NRI to EQ gradients is a result of great and difficult to explain variability in the index values in low ranges of BMWPpl and MMI. It can be assumed that the use of more advanced and precise methods to assess the phylogenetic relationships among benthic animals, e.g. taking into account the relative abundance of taxa (e.g. Allen et al., 2009) would further increase the benefits of their application. However, keeping the family level of determination could allow to exploit the existing bio-monitoring databases. We suggest that analysed indices of $\mathrm{PD}$, especially MDis, are related with EQ measured by macrobenthos structure in such a strong and unambiguous way to be taken into account as potential metrics in selection procedures of biological assessment.

It should be emphasized that the lack of strong relationship between PD and most of the analysed environmental factors may be the result of great divergence of analysed environments, which belonged probably to different categories in terms of their biotic and abiotic parameters (Heino et al., 2007; Roque et al., 2014). The methodology used in present paper, based on independent analysis of watercourses belonging to different abiotic and biocenotic types could result in higher predictive value of PD indices. 
Potential advantages and disadvantages of PD indices were presented and compared by Saito et al. (2015). Only one of the three indices tested and statistically filtered in their study were classified as sensitive to environmental impact, but their database were artificially limited only to insects. However, they suggest that future biotic indices should consider including new PD indices to properly monitor biodiversity. At least one of the three serious drawbacks of PD indices described by Saito et al. (2015) as impossible to ignore seems to be very important: need for designing a phylogenetic supertree for each assessed ecoregion.

The highest correlation with both types of EQ was observed for the simplest parameter - FR (Tab. 2). Its strong correlation is, however, a result of an obvious error: number of families is not an independent variable but, in fact, a hidden factor in both indices: BMWPpl and MMI. This means that sites with high EQ measured by BMWPpl and MMI are those inhabited by macrobenthic organisms belonging to a relatively higher number of families. Values of BMWPpl obviously increase with the number of families, being the sum of the scores for each family found in a sample. MMI is a multimetric index having a form of weighted arithmetic mean, and FR is one of six metrics used for its calculation. This implies that FR should not be directly compared with other EQ predictors because it is not an independent or explained variable. Additive and mathematically simple nature of index BMWPpl, whose values increase directly with the number of families may be the main reason why it correlates stronger than complex, multimetric index MMI with different measures of biodiversity, including the PD.

BMWPpl seems to be a much better way to evaluate EQ than MMI when carried out on the basis of different types of biological diversity, including PD. It is surprising that the coefficient of linear regression between Shannon index and MMI, calculated on data from 1114 sampling sites by Bis and Mikulec (2013), equaled 0.6114, was much lower than that calculated in the present study on the basis of 864 sites (between 0.455 and 0.491 in different biocoenotic types of watercourses). Two methodological factors seem to be probable causes of the much weaker correlation of MMI with TD and PD indices as well as FR. First, at low values of FR, the variability of MMI values is even six times higher than values of BMWPpl, which clearly may influence $R^{2}$ coefficients because mathematically transformed FR is included in all tested PD and TD indices. This difference may be the result of improper macrobenthos sampling - e.g. not all types of bottom substrates present at a site are taken into account. Methodology of multihabitat sampling in accordance with the procedure RIVECO is extremely complicated (Bis and Mikulec, 2013) and difficult to standardize, especially in large and medium-sized rivers (types V and VI), and could significantly limit the reliability of the assessment. Second, the cause of the difference can be the fixed-count method used in the procedure MMI. At high abundance of one of the families present in a watercourse, certain taxa occurring with a high frequency, but always in small number (typically Hirudinea, Odonata and Decapoda), are not reported in the protocol although they are present in the sample. This kind of bias can drastically reduce the value of diversity and is difficult to estimate.
Acknowledgements. Authors are grateful to Polish Head Inspectorate of Environmental Protection and to staff of RIEP. Authors thank Reviewers for valuable and useful comments and suggestions. The study was financially supported by National Center of Scientific Research, Republic of Poland for the project 2011/01/B/NZ9/02590.

\section{References}

Allen B, Kon M, Bar-Yam Y. 2009. A new phylogenetic diversity measure generalizing the Shannon index and its application to phyllostomid bats. Am Nat 174: 236-243.

Armitage PD, Moss D, Wright JF, Furse MT. 1983. The performance of a new biological water quality score system based on macroinvertebrates over a wide range of unpolluted running water sites. Water Res 17: 333-347.

Bailey RC, Norris RH, Reynoldson TB. 2004. Bioassessment of freshwater ecosystems. USA: Springer, $170 \mathrm{p}$.

Bertrand Y, Pleijel F, Rouse GW. 2006. Taxonomic surrogacy in biodiversity assessments, and the meaning of Linnaean ranks. Syst Biodivers 4: 149-159.

Bis B, Mikulec A. 2013. Przewodnik do oceny stanu ekologicznego rzek na podstawie makrobezkręgowców bentosowych (The guide to ecological status assessment of the rivers on the basis of benthic macro-invertebrates). Warszawa: Biblioteka Monitoringu Środowiska (in Polish).

Carew ME, Miller AD, Hoffmann AA. 2011. Phylogenetic signals and ecotoxicological responses: potential implications for aquatic biomonitoring. Ecotoxicology 20: 595-606.

Clarke KR, Warwick RM. 1999. The taxonomic distinctness measure of biodiversity: weighting of step lengths between hierarchical level. Mar Ecol Prog Ser 184: 21-29.

Crozier RH, Dunnett LJ, Agapow PM. 2005. Phylogenetic biodiversity assessment based on systematic nomenclature. Evol Bioinform 1: 11-36.

Encyclopaedia of Life. 2011. http://eol.org/.

Faith DP. 2015. Phylogenetic diversity, functional trait diversity and extinction: avoiding tipping points and worst-case losses. Philos Trans R Soc B 370: 0-11. DOI:10.1098/rstb.2014.0011.

Faith DP, Baker AM. 2006. Phylogenetic diversity (PD) and biodiversity conservation: some bioinformatics challenges. Evol Bioinform Online 2: 121-128.

Faith DP, Lozupone CA, Nipperess D, Knight R. 2009. The cladistic basis for the phylogenetic diversity (PD) measure links evolutionary features to environmental gradients and supports broad applications of microbial ecology's "phylogenetic beta diversity" framework. Int J Mol Sci 10: 4723-4741.

Furse, M, Hering D, Moog O, et al. 2006. The STAR project: context, objectives and approaches. Hydrobiologia 566: 3-29.

Gallardo B, Gascón S, Quintana X, Comín FA. 2011. How to choose a biodiversity indicator - redundancy and complementarity of biodiversity metrics in a freshwater ecosystem. Ecol Indic 11: 1177-1184.

Heino J, Soininen J. 2007. Are higher taxa adequate surrogates for species-level assemblage patterns and species richness in stream organisms? Biol Conserv 137: 78-89.

Heino J, Mykrä H, Hämälainen H, Aroviita J, Muotka T. 2007. Responses of taxonomic distinctness and species diversity indices to anthropogenic impacts and natural environmental gradients in stream macroinvertebrates. Freshwater Biol 52: 1846-1861.

Hering D, Feld CK, Moog O, Ofenböck T. 2006. Cook book for the development of a multimetric index for biological condition of aquatic ecosystems: experiences from the European AQEM and STAR projects and related initiatives. Hydrobiologia 566: 311-324. 
P. Koperski and R. Meronka: Knowl. Manag. Aquat. Ecosyst. 2017, 418, 16

Hilsenhoff WL. 1988. Rapid field assessment of organic pollution with a family-level biotic index. J North Am Benthol Soc 7: 65-68.

Jones FC. 2008. Taxonomic sufficiency: the influence of taxonomic resolution on freshwater bioassessment using benthic macroinvertebrates. Environ Rev 16: 45-69.

Koperski P. 2010. Diversity of macrobenthos in lowland streams: ecological determinants and taxonomic specificity. J Limnol 69: 88-101.

Koperski P. 2011. Diversity of freshwater macrobenthos and its use in biological assessment: a critical review of current applications. Environ Rev 19: 16-31.

Lepori F, Hjerdt N. 2006. Disturbance and aquatic biodiversity: reconciling contrasting views. Bioscience 56: 809-818.

Lewin I, Jusik S, Szoszkiewicz K, Czerniawska-Kusza I, Ławniczak AE. 2014. Application of the new multimetric MMI PL index for biological water quality assessment in reference and human-impacted streams (Poland, the Slovak Republic). Limnologica 49: 42-51.

Lydy MJ, Crawford CG, Frey JW. 2000. A comparison of selected diversity, similarity, and biotic indices for detecting changes in benthic-invertebrate community structure and stream quality. Arch Environ Contam Toxicol 39: 469-479.

Magurran AE. 2004. Measuring biological diversity. Blackwell Publishing, Oxford, $256 \mathrm{p}$.

NCBI Taxonomy. November 2014. http://www.ncbi.nlm.nih.gov/ taxonomy.

Pielou EC. 1975. Ecological diversity. New York: Wiley, 165 p.

Roque FO, Guimarães EA, Ribeiro MC, Escarpinati SC, Suriano MT, Siqueira T. 2014. The taxonomic distinctness of macroinvertebrate communities of Atlantic Forest streams cannot be predicted by landscape and climate variables, but traditional biodiversity indices can. Braz J Biol 74: 991-999.

Saito VS, Siqueira T, Fonseca-Gessner AA. 2015. Should phylogenetic and functional diversity metrics compose macroinvertebrate multimetric indices for stream biomonitoring? Hydrobiologia 745: 167-179.

Schweiger O, Klotz S, Durka W, Kühn I. 2008. A comparative test of phylogenetic diversity indices. Oecologia 157: 485-495.

Šiling R, Urbanič G. 2016. Do lake littoral benthic invertebrates respond differently to eutrophication, hydromorphological alteration, land use and fish stocking? Knowl Manag Aquat Ecosyst 417: 35 .

Tree of Life. 1995-2005. http://tolweb.org/tree/.

Usseglio-Polatera P, Bournaud M, Richoux P, Tachet H. 2000. Biological and ecological traits of benthic freshwater macroinvertebrates: relationships and definition of groups with similar traits. Freshwater Biol 43: 175-205.

Vamosi JC, Vamosi SM. 2007. Body size, rarity, and phylogenetic community structure: insights from diving beetle assemblages of Alberta. Divers Distrib 13: 1-10.

Warwick RM, Clarke KR. 1995. New 'biodiversity' measures reveal a decrease in taxonomic distinctness with increasing stress. Mar Ecol Prog Ser 129: 301-305.

Water Framework Directive. 2000. Directive of the European Parliament and of the Council 2000/60/EC Establishing a Framework for Community Action in the Field of Water Policy, 1997/0067(COD), C5-0347/2000, LEX 224, PE-CONS 3639/1/00, REV1.

Webb CO. 2000. Exploring the phylogenetic structure of ecological communities: an example for rain forest trees. Am Nat 156: $145-155$.

Wikispecies. August 2014. https://species.wikimedia.org.

Winter M, Devictor V, Schweiger O. 2013. Phylogenetic diversity and nature conservation: where are we? Trends Ecol Evol 28: 199-204.

Yoccoz NG, Nichols JD, Boulinier T. 2001. Monitoring of biological diversity in space and time. Trends Ecol Evol 16: 446-453.

Cite this article as: Koperski P, Meronka R. 2017. Environmental quality of a stream can be better predicted by phylogenetic than by taxonomic diversity. Knowl. Manag. Aquat. Ecosyst., 418, 16. 